\title{
Metodologia integrada para mapeamento de falhas: uma proposta de utilização conjunta do mapeamento de processos com as técnicas FTA, FMEA e a análise crítica de especialistas
}

\author{
Ualison Rebula de Oliveira ${ }^{\mathrm{a}, *}$, Emerson José de Paiva ${ }^{\mathrm{b}}$, Dagoberto Alves de Almeida \\ a,*ualison.oliveira@gmail.com, UNESP, Brasil \\ bemersonjpaiva@gmail.com, UNIFEl, Brasil \\ cdagoberto@unifei.edu.br, UNIFEl, Brasil
}

\begin{abstract}
Resumo
As falhas representam não conformidades nas atividades produtivas, de tal modo que pesquisas para seu controle e prevenção são, no mínimo, desejáveis. Na literatura sobre o assunto, observa-se uma gama variada de técnicas, porém, quase sempre, usadas isoladamente e, em poucos casos, no setor de serviços. Observando essa lacuna, propõe-se uma metodologia de Mapeamento de Falhas que integra diferentes abordagens que se complementam, aproveitando-se o potencial e o benefício de cada técnica para análise e controle de falhas. Para a consecução dessa proposta, efetuouse uma pesquisa bibliográfica para conceituação e entendimento das técnicas utilizadas, um estudo e análise de integração dessas técnicas e, por fim, um exemplo real de aplicação em processo notarial de serviço, tema este ainda não explorado na literatura pertinente e, portanto, bastante auspicioso. Como resultado, observa-se uma ferramenta que permite uma visualização completa e objetiva das atividades desencadeadas pelos processos, seus pontos críticos e suas potenciais falhas, podendo ser aplicada com propriedade em empresas de prestação de serviços.
\end{abstract}

Palavras-chave

Mapeamento de falhas. Serviços judiciais. FTA. FMEA.

\section{Introdução}

Segundo Fagundes e Almeida (2004), a necessidade cada vez maior de melhorar a confiabilidade tem popularizado vários métodos e técnicas para a minimização/eliminação de falhas. Estes métodos e técnicas têm como objetivo melhorar a confiabilidade de produtos ou processos, ou seja, aumentar a probabilidade de um item desempenhar sua função sem falhas. Desses métodos e técnicas, Jung et al. (2005) afirmam que a Árvore de Análise de Falhas, também conhecida como FTA (Fault Tree Analysis), é a mais comumente utilizada. Araujo et al. (2001) ampliam o rol de técnicas adicionando a Análise dos Modos e Efeitos de Falhas, também conhecida como FMEA (Failure Mode and Effects Analysis). Esta ampla utilização, segundo Araujo et al. (2001), se deve, provavelmente, ao fato destas técnicas serem as únicas citadas textualmente na norma ISO 9004, subitem 8.4. Teng et al. (2006) também ressaltam que a utilização da FMEA é requisito obrigatório da norma QS 9000 (uma versão automotiva da norma ISO 9000), sendo este um dos motivos de sua ampla utilização. Vale mencionar também a ISO/TS 16949, norma automotiva elaborada conjuntamente pelos membros do IATF (International Automotive Task Force), grupo composto por General Motors ${ }^{\circledR}$, Ford $^{\circledR}$, Daimler Chrysler $^{\circledR}$, BMW ${ }^{\circledR}$, PSA Citroen ${ }^{\circledR}$, Volkswagen ${ }^{\circledR}$, Renault ${ }^{\circledR}$ e Fiat ${ }^{\circledR}$.

Aliado a essas duas técnicas, julga-se que a compreensão do processo também deva ser enfatizada, pois, conforme Pinho et al. (2006), a visão do processo permite uma melhor identificação das falhas, uma vez que o entendimento do desencadeamento das atividades do processo dá à empresa uma compreensão mais clara das tarefas executadas no negócio. Para tanto, recomenda-se a utilização de técnicas de mapeamento de processos (HUNT, 1996). 
Este artigo propõe uma quarta e última técnica a ser aglutinada à análise de falhas: a Análise de Processos Críticos por Especialistas, que doravante será designada pela sigla APCE. A APCE segmenta os diversos processos mapeados em críticos e não críticos, em que especialistas que participam do negócio mapeado opinam quais processos devem ser expandidos em uma FTA com seu consequente desdobramento em uma FMEA. Em termos metodológicos a APCE não é algo novo, apenas foca a preocupação do analista na definição dos aspectos críticos. Ainda, a APCE considera métodos consagrados tais como o Delphi e o Júri de Especialistas para condução da discussão coletiva dos processos em análise, sendo que o estudo da criticidade dos processos, orientado inicialmente pelos especialistas, continua na sequência com o auxílio conceitual da FTA e da FMEA.

Diante do exposto, este artigo possui como objetivo principal a proposição de um método integrativo para a minimização/eliminação de falhas. Tal propósito será conduzido mediante uma revisão bibliográfica das várias técnicas de mapeamento de processos e de mapeamento de falhas, as quais serão apresentadas sob um viés sistêmico. 0 método integrativo será aplicado em um caso prático de um ambiente de serviço ainda não explorado na literatura de gestão de operações, os processos de natureza jurídica, especificamente, cartoriais.

Fato é que os conhecimentos aqui abordados são amplamente pragmáticos e altamente difundidos pela comunidade do setor industrial. Entretanto, fora desse ambiente, no qual a gestão de operações pode também estar presente, observa-se certa dificuldade de aplicação das técnicas aqui descritas, ainda mais quando usadas conjuntamente. Dúvidas por onde se inicia e aonde se termina um mapeamento de falhas é uma realidade para várias classes profissionais, como por exemplo, funcionários de serviços cartoriais. A falta de experiência em aplicar estas ferramentas e, consequentemente, a não compreensão de como e quando utilizá-las, especificamente de uma significativa parcela de potenciais usuários do setor de serviços, motivaram a consecução da presente pesquisa. Além disso, pouco se lê ou se ensina sobre uma metodologia integrada para mapeamento de falhas em empresas de prestação de serviços (RATH, 2008). Dessa forma, justifica-se a proposição de um método que trará facilidade e agilidade para seus usuários, propiciando uma ferramenta de simples aplicação, principalmente para os profissionais do setor de serviços.

Para a realização desse trabalho, a seção 2 aborda o referencial teórico utilizado; a seção 3 analisa e discute a integração das técnicas descritas na seção anterior, propondo um método integrativo; a seção 4 aplica a metodologia proposta em um caso prático e real; a seção 5 relata as ações decorrentes da pesquisa e, por fim, a seção 6 conclui o presente estudo.

\section{Referencial teórico}

Esta seção trata do referencial teórico nos temas associados à presente pesquisa. Assim, são apresentadas as várias definições e discriminação dos tipos de falhas e sua segmentação. Em seguida, são descritas a definição e a tipologia do mapeamento de processos, seguidas da análise dos processos críticos por especialistas. Esta seção trata, também, do levantamento de falhas por meio da Árvore de Análise de Falhas e da Análise dos Modos e Efeitos de Falhas, encerrando-se com um levantamento dos vários modelos integrativos disponíveis na literatura.

\subsection{Definição, discriminação de tipos e segmentação de falhas}

Conforme Blache e Shrivastava (1994) salientam, as falhas são eventos que determinam a inadequação de um recurso para o uso. Rausand e Oien (1996) definem falha como sendo o fim da habilidade de um item executar uma função exigida. Almeida et al. (2006) definem falha como sendo um evento indesejado e responsável por erros e mau funcionamento do processo produtivo.

Segundo Slack et al. (2002), embora nenhuma operação produtiva seja indiferente às falhas, em algumas é crucial que os produtos e serviços não falhem, culminando em prejuizos que podem alcançar grandes proporções - aviões em vôo, fornecimento de eletricidade a hospitais e funcionamento dos freios de um automóvel, por exemplo. Em outras elas são incidentais e podem não representar grande impacto ao processo, podendo, inclusive, ser negligenciadas, tais como a falha da luz interna de iluminação do porta-luvas de um automóvel. Ainda, atividades de serviços, tais como processos administrativos, judiciais ou extrajudiciais - como o objeto de estudo do presente trabalho estão sujeitos a falhas de projeto e condução das etapas requeridas com a possibilidade de incorreções que penalizam o exercício pleno do propósito do processo. Este trabalho contribui por aplicar em serviços, especificamente na área jurídica, conceitos de gestão de falhas já consolidados em numerosas aplicações das mais variadas áreas de atividade (aeronáutica, automobilística, energia, etc.). 
Assim, as organizações precisam discriminar as diferentes falhas e prestar atenção especial àquelas que são inerentemente críticas ou que possam repercutir negativamente na produção ou serviço. Nesse contexto, Blache e Shrivastava (1994) discriminam os diferentes tipos de falhas em Intermitente e Estendida, Completas e Parciais e, em última instância, Graduais ou Súbitas, resultando em falhas de degradação, ou falhas catastróficas. Além dessa caracterização, Rausand e Oien (1996) segmentam as falhas como decorrentes de desgaste, mau uso ou inerentes à fragilidade de materiais ou projeto construtivo.

\subsection{Mapeamento de processos: sua definição e tipologia}

Cheung e Bal (1998) definem mapeamento de processos como a técnica de se colocar em um diagrama o processo de um setor, departamento ou organização, para orientação em suas fases de avaliação, projeto e desenvolvimento.

Segundo Mello e Salgado (2005), para se gerenciar um processo é necessário, primeiramente, visualizá-lo. Assim, o mapeamento é realizado para representar as diversas tarefas necessárias e a sequência que elas ocorrem para a realização e entrega de um produto ou serviço. Dessa forma, segundo Tseng et al. (1999), o mapeamento de processos deve ser apresentado sob a forma de uma linguagem gráfica que permita: expor os detalhes do processo de modo gradual e controlado; descrever o processo com precisão; focar a atenção nas interfaces do mapa do processo; e fornecer uma análise de processos consistente com o vocabulário do projeto.

Quanto às técnicas de mapeamento, a literatura sobre o assunto apresenta inúmeros tipos com diferentes enfoques. Assim, torna-se imprescindível selecionar a técnica adequada para cada situação em que se necessita empregar o mapeamento de processos. Conforme Leal et al. (2003), Leal (2003) e Mello e Salgado (2005), as principais técnicas de mapeamento de processos são:

a) Fluxograma de processo, utilizado para se registrar um processo de maneira compacta, por meio de alguns símbolos padronizados (BARNES, 2004);

b) Mapofluxograma, utilizado para representar o processo em uma planta de edifício ou na própria área em que a atividade se desenvolve (BARNES, 2004);

c) Integrated Computer Aided Manufacturing Definition (IDEF), que permite uma análise completa e complexa dos processos por meio de suas entradas, saídas, restrições e interações, empregando a "família" IDEF (MAYER et al., 1992; GROVER; KETTINGER, 1995; CHEUNG; BAL 1998; TSENG et al., 1999), com suas variações e particularidades;

d) Diagrama sistemático do Unified Modeling Language (UML), criado para desenvolvimento de sistemas de software e adaptado para se modelar sistemas diversos que não os de software (WILCOX; GURAU, 2003);

e) Service Blueprint, uma técnica desenvolvida para o mapeamento dos processos de serviços, diferenciando-se dos fluxogramas por considerar o aspecto da interação com o cliente, representando todas as transações que constituem o processo de entrega do serviço, inclusive aquelas atividades de retaguarda (FITZSIMMONS; FITZSIMMONS, 2000; FLIEB; KLEINALTENKAMP, 2002); e

f) Mapa do serviço, uma técnica para o mapeamento dos serviços derivada do Service Blueprint que envolve a gestão do serviço como um todo e não somente o processo de entrega do serviço. Trata-se de uma técnica gerencial para representar, cronologicamente, as tarefas e atividades realizadas pelo cliente, pelo pessoal de linha de frente e pelo pessoal de suporte no desempenho de um serviço (KINGMAN-BRUNDAGE, 1995).

As seis técnicas apresentadas acima se prestam ao mapeamento de processos de serviços. Para o caso em pauta, serviços cartoriais, a justificativa da técnica utilizada será aventada na seção 4 (aplicação do modelo integrativo de processos e falhas em um caso prático).

\subsection{Análise dos processos críticos por especialistas}

A Análise dos Processos Críticos por Especialistas (APCE) objetiva identificar no mapa de processo as etapas essenciais do negócio em análise, bem como destacar os aspectos críticos potencializadores de falhas.

Trata-se de uma forma de segmentar o processo em análise em duas categorias: os elementos, etapas e atividades críticas das não críticas. As atividades críticas são aqueles que implicam na ocorrência da falha, culminando no não cumprimento do propósito do sistema, comprometendo os resultados organizacionais. Já as não críticas são aquelas que prejudicarão alguma etapa do processo, não comprometendo, porém, a concretização das metas do sistema. Obviamente, a classificação entre crítico e não crítico é sempre comparativa e sujeita a polêmicas e controvérsias, daí a importância da análise ser feita por mais de uma pessoa. 
Para condução da APCE, sugere-se a utilização de qualquer método de pesquisa qualitativa, obviamente guardadas suas especificidades, podendo-se citar o método Delphi (GREEN et al., 2007), o qual, segundo Okoli e Pawlowski (2004), é reconhecido como um dos melhores instrumentos de previsão qualitativa, sendo indicado, principalmente, quando não existam dados históricos a respeito do problema que se investiga ou, em outros termos, quando faltam dados quantitativos referentes a ele. 0 princípio do método Delphi é intuitivo e interativo. Sua realização implica a constituição de um grupo de especialistas em determinada área do conhecimento, que respondem a uma série de questões. Os resultados dessa primeira fase são analisados. A síntese dos resultados é comunicada aos membros do grupo que, após tomarem conhecimento, respondem novamente (MACCARTHY; ATTHIRAWONG, 2003).

De uma perspectiva mais ampla, painéis de especialistas (GOHO et al., 2003; VERGARA, 2006) permitem pela sua interação a troca de experiências e impressões, que muito contribuem para evitar uma postura idiossincrática acerca do processo em estudo. Inaki et al. (2006) corroboram as contribuições de Maccarthy e Atthirawong (2003) ao defenderem que esse tipo de atividade deve ser efetuado por pessoas com amplos conhecimentos do negócio (especialistas) que estejam envolvidas no processo, permitindo, assim, uma análise e discussão de cada etapa gradual e individualmente. Dessa forma, por meio da aplicação de um método de condução coletiva de discussões e emissão de pareceres, análises de criticidade dos processos e atividades podem ser formuladas por especialistas do negócio mapeado. Os especialistas opinam sobre quais processos devem ser expandidos em uma FTA, dando prosseguimento ao mapeamento integrado de falhas.

A APCE considera duas etapas distintas: a análise entre processos e a análise intra-processo realizada sobre aquele anteriormente selecionado. Assim, tem-se uma análise macro e uma análise mais detalhada, ambas realizadas pelos especialistas. Especificamente, a análise intra-processo considera três atividades sequenciais: (1) a identificação das etapas, fatores e recursos pertinentes; (2) a ordenação dos elementos em análise, de acordo com sua criticidade (priorização) e; (3) a segmentação em categorias similares de importância (críticos) e segregação dos fatores considerados de menor importância (não críticos). A Figura 1 ilustra 0 método da APCE.

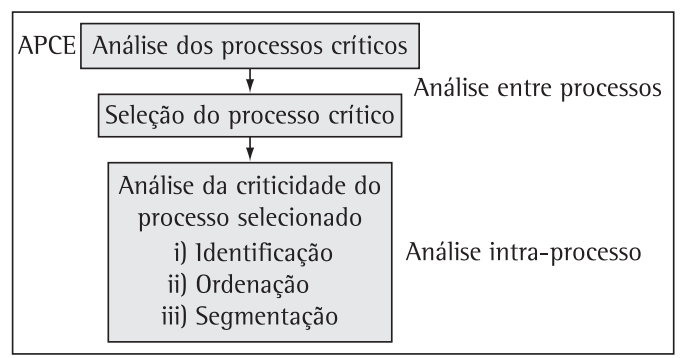

Figura 1. 0 método APCE.

A APCE poupará tempo e economizará recursos em desdobramentos desnecessários de processos não críticos em FTA e FMEA, uma vez que somente os processos críticos que comprometem o funcionamento do sistema terão seus mapeamentos de falhas concluídos.

No entanto, vale ressaltar que não se defende a tese de que somente os processos críticos devam ser mapeados, mas sim de se priorizar os esforços em prol dos processos que mais impactam o negócio em estudo, orientando a análise de falhas por ordem de gravidade e urgência, dando sequência ao levantamento de falhas por meio de suas relações de causa e efeito.

\subsection{Levantamento de falhas por meio da árvore de análise de falhas}

A análise da árvore de falhas, do original em inglês Fault Tree Analysis(FTA), é uma representação gráfica padronizada capaz de fornecer bases objetivas para análise de modos comuns de falhas. 0 método inicia com uma falha particular do sistema, também denominada de efeito ou evento de topo, desdobrando-a em uma árvore lógica até as falhas básicas, também denominadas de causas ou eventos primários (VOLLERTT JUNIOR, 1996; LIN e WANG, 1997; LONG et al., 2000).

Quanto à sua forma gráfica, conforme se observa na literatura, os símbolos mais utilizados para a construção da FTA são o retângulo, o círculo e os operadores lógicos "ou" e "e". O retângulo denota um evento de falha que é o resultado de uma combinação lógica de eventos de falha. 0 círculo denota um evento de falha básico ou a falha de um componente elementar. A Porta lógica E implica que o evento de saída só ocorre se todos os de entrada ocorrerem. A Porta lógica OU denota que evento de saída só ocorre se pelo menos um dos de entrada ocorrer. A Figura 2 exemplifica os operadores lógicos mais comuns de uma FTA. 


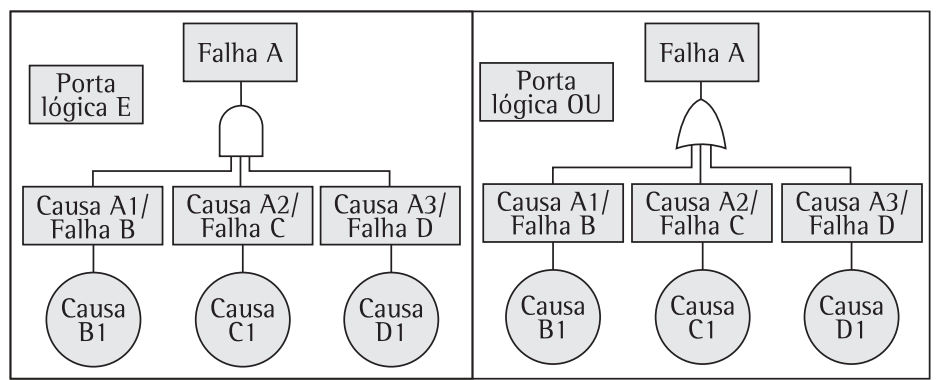

Figura 2. Exemplo de FTA.

Quanto à obtenção da probabilidade de ocorrência do evento de topo, Yugi et al. (2006) propõem uma metodologia embasada em três algoritmos que garantem eficiência e exatidão nesse tipo de cálculo, não sendo aprofundado aqui por fugir aos propósitos da presente pesquisa. Já Almeida e Pinho (2005) apresentam um algoritmo associado ao caminho crítico das relações de causa e efeito de maior probabilidade de ocorrência, conduzindo o gestor a adotar intervenções capazes de permitir a solução da falha em questão.

\subsection{A análise dos modos e efeitos de falhas}

A Análise dos Modos e Efeitos de Falhas, do original em inglês Failure Mode and Effects Analysis (FMEA) é uma metodologia sistemática que permite identificar potenciais falhas de um sistema, projeto e/ou processo, com o objetivo de eliminar ou minimizar os riscos associados, antes que tais falhas aconteçam (YANG et al. 2006).

Conforme Helman e Andery (1995), a FMEA é usada para identificar todos os possíveis modos potenciais de falhas e determinar o efeito de cada uma sobre o desempenho do sistema (produto ou processo), mediante um raciocínio basicamente dedutivo. 0 uso consistente da FMEA pode permitir a identificação de problemas que não haviam sido antecipados e, consequentemente, ao estabelecimento de prioridades para a correção (PALADY, 1997).

Araújo et al. (2000) advogam a existência de dois tipos de FMEA: de produto (denominada geralmente FMEA de projeto) e de processo. $\mathrm{Na}$ FMEA de produto, identificam-se cada componente do sistema e os possíveis modos de falha associados, bem como seus efeitos no sistema em questão e no produto como um todo. Para Bastos (2006), a FMEA de produto analisa e avalia as funções, materiais utilizados, componentes, tolerâncias, etc. A FMEA de processo, por sua vez, é utilizada para a análise detalhada de sistemas produtivos que possam, ocasionalmente, afetar a confiabilidade prevista no produto, identificando os modos de falhas potenciais no processo e seus efeitos no cliente (PALADY, 1997). Esta análise auxilia também na identificação das variáveis de processo que devem ser controladas para priorizar as tomadas de ações preventivas ou corretivas. Conforme Bastos (2006), a realização da FMEA do processo inicia-se a partir de um fluxograma de processo, o qual deve indicar as características do produto e do processo detalhado a cada operação.

As informações pertinentes que devem fazer parte de um formulário FMEA são sugeridas por Palady (1997), e um procedimento construtivo é apresentado por Sharma et al.(2005).

\subsection{Modelos integrativos}

Essa seção abordará algumas pesquisas que propuseram modelos integrativos para a análise e o tratamento de falhas, aprofundando, assim, o referencial teórico.

Mahanti e Antoni (2005), por exemplo, destacam a integração de seis ferramentas utilizadas na abordagem Six Sigma para analisar, medir e prever falhas nos elementos de programação de software, das quais se destacam o mapeamento de processos e a FMEA.

Outra integração de procedimentos para análise de falhas que se observa na literatura está relacionada com a preocupação de uma análise mais consistente do comportamento da falha, de forma que seja possível planejar ações mais apropriadas para sua minimização/mitigação. Para isso, Sharma et al. (2007) propuseram a integração entre as ferramentas RCA (Root Cause Analysis), NHPPP (non-homogeneous Poisson point process) e a FMEA, de forma a construir uma estrutura integrada capaz de facilitar a tomada de decisão inerente a falhas. A integração dessas ferramentas propõe a análise da não confiabilidade do sistema pelas técnicas RCA e FMEA, de forma a criar uma 
base de conhecimento para tratar dos problemas relativos ao processo e/ou não confiabilidade do produto. Já o modelo NHPPP é utilizado para aperfeiçoar as decisões da manutenção (reparo ou recolocações) baseadas em dimensões do custo, ajudando o analista de manutenção durante o processo de desenvolvimento da estratégia de manutenção apropriada para cada modo de falha.

Shahin (2004) ressalva que, em quase todas as pesquisas existentes sobre FMEA, a "severidade" está sendo determinada sob o ponto de vista dos "projetistas" do FMEA e não dos clientes impactados pelos produtos e serviços. Diante dessa situação, esse autor propõe a integração da FMEA com o Modelo de Kano, exatamente para permitir que o RPN seja obtido a partir das percepções dos clientes.

Omodelo deKano foi desenvolvido primeiramente pelo Dr. Noriaki Kano em 1984 (KANO/ SHAHIN) para categorizar os atributos de um produto ou de um serviço, com base em quão bons seriam e se poderiam satisfazer as necessidades dos clientes. Assim, propõe-se um modelo de FMEA orientado pelo cliente. Com esta finalidade, o Modelo de Kano foi integrado ao índice de severidade.

Outro tipo de integração é apresentado por Fernandes e Rebelato (2006), combinando o QFD (Quality Function Deployment) e o FMEA. 0 emprego dessas duas técnicas é ilustrado por meio de um exemplo fictício de aplicação. Segundo os autores, estes dois métodos são frequentemente vistos como ferramentas não relacionadas e sua integração, quando ocorre, é tradicionalmente insuficiente e mal explorada. Em decorrência disso, os autores propõem algumas alterações necessárias em ambos os métodos a partir da identificação e análise das "saídas" de QFD e "entradas" de FMEA, buscando novas possibilidades de integração, chegando a uma proposta com maior grau de inter-relacionamento entre os métodos do que a abordagem tradicional, visando incrementar a eficiência da integração e tornar mais clara sua aplicação.

No que concerne à FTA, Xie et al. (2000) sugerem sua integração a abordagens que permitam sua utilização de forma mais produtiva. Segundo esses autores, a maioria dos estudos realizados sobre FTA está relacionada à como construir uma árvore de falha e a como realizar sua análise. Como na maioria das situações práticas, os recursos são limitados e, devido a isso, exige-se que somente os itens críticos sejam submetidos à análise e melhoria e aperfeiçoamento. Consequentemente, há uma necessidade de dar a prioridade a esforços para atribuição de recursos. Com esse propósito, Xie et al. (2000) propuseram uma metodologia para definição do elemento ou evento básico mais importante que afeta a confiabilidade de todo o sistema. Esse método faz uso de cálculos de medidas de importância e criticidade, tais como as medidas de Birnbaum e Vesely-Fussel.

No campo da medicina, Rath (2008) examina a aplicação dos conceitos da gerência de qualidade e da garantia de qualidade nas práticas de radioterapia. Sua pesquisa propõe uma aproximação sistemática que incorpora uma série de técnicas utilizadas na engenharia industrial para a melhoria dos resultados dos processos de natureza médica com o objetivo de reduzir riscos no tratamento e melhorar a segurança do paciente. Essas ferramentas contemplam o fluxograma do processo, a FMEA e a FTA. Segundo esse autor, uma das maiores dificuldades na implantação dessa metodologia de análise de falhas está na falta de experiência dos médicos, enfermeiros e profissionais da saúde em aplicar estas ferramentas e consequentemente não compreenderem como e quando usá-las. Assim, esse autor desenvolveu uma metodologia para análise de falhas com base naquelas ferramentas, com vistas a apoiar a comunidade médica em sua aplicação.

Nesse momento ressalta-se que o presente trabalho, Modelo Integrativo de Mapeamento de Processos e de Falhas com Análise de Especialistas, possui um objetivo similar ao trabalho desenvolvido por Rath (2008), visto que, infelizmente, pouco se lê sobre uma metodologia para mapeamento de falhas em serviços, especificamente como o caso prático do cartório estudado, propiciando assim uma ferramenta de simples aplicação ainda que com material bibliográfico oriundo do setor industrial.

\section{Proposição do modelo conceitual de mapeamento de falhas}

Conforme Helman e Andery (1995), à medida que resultados indesejados dos processos (falhas) são percebidos, atua-se metodicamente sobre eles para achar a sua causa fundamental e bloqueá-la. lsso pode ser feito mediante a aplicação do ciclo PDCA à eliminação de efeitos indesejados, bem como para a introdução de melhorias. A presente pesquisa fornece subsídios para a consecução da primeira etapa do PDCA no contexto de sua aplicação na gestão de falhas, i. e., por meio da identificação do problema, sua observação, análise e plano de ação.

A identificação do problema (da falha) se inicia com a aplicação do mapeamento do processo, visto que os fluxogramas das etapas consideradas do processo auxiliam na verificação de como suas 
partes estão fisicamente ligadas e relacionadas, visando à compreensão da sequência lógica de procedimentos. Essa técnica é sucedida pela aplicação da APCE para identificação dos processos críticos, priorização por ordem de relevância, para posterior desdobramento e detalhamento. Inicia-se, em seguida, a observação e análise da falha, gerando-se a FTA. A FTA, por proporcionar um encadeamento lógico das falhas de um sistema e possibilitar a visualização das correlações entre uma causa primária ou intermediária com o evento de topo (ARAUJO et al., 2001) subsidia a elaboração da FMEA de processo, visto que cada causa de falha, primária ou intermediária, pode ser convertida em uma FMEA. Finalmente é gerada a FMEA, por se constituir no mais alto nível de detalhamento com todos os modos de falhas, seus efeitos, causas e ações de mitigação/correção recomendadas. A FTA e a FMEA fornecem pistas para a execução de melhorias nos sistemas, mediante a descoberta de pontos problemáticos relacionados às falhas, sendo advogado seu uso conjunto (HELMAN; ANDERY, 1995).

Ainda segundo Helman e Andery (1995), essas duas ferramentas se unem devido às suas diferenças em relação ao tratamento da falha, que são:

- Finalidade: a FTA estuda os "eventos de topo" considerados sérios para demandar uma análise posterior, enquanto a FMEA tenta avaliar a confiabilidade de cada subprocesso;
- Procedimento: o ponto de partida da FTA é uma lista dos modos de falhas para as quais se deseja dar uma solução. A FMEA identifica possíveis modos de falha, efeitos e causas; e

- Visualização: a FTA permite a análise conjunta de causas que conduzirão ao evento de topo. A FMEA analisa cada causa de um modo de falha e o seu efeito, separadamente.

A integração entre as quatro técnicas é ilustrada por meio do algoritmo descrito na Figura 3. Salienta-se ainda - como abordado no tópico 4 - que a análise entre processos precede a análise intrafalha (identificação das etapas, fatores e recursos pertinentes; ordenação dos elementos em análise de acordo com sua criticidade (priorização); e segmentação em categorias similares de importância). Desta forma, os especialistas colaboram na fase inicial julgando os macroprocessos que devam ser objeto de estudo. Na aplicação da metodologia de mapeamento de falhas no caso prático, que será abordada como exemplo na próxima seção, a lavratura de escritura é reconhecida como o principal processo de um cartório.

Na FTA parte-se do efeito e chega-se à causa; Na FMEA o ponto problemático é enfocado a partir da causa, raciocinando na direção do efeito (falhaproblema).

Com o intuito de auxiliar o leitor na síntese das questões em discussão, o Quadro 1 apresenta

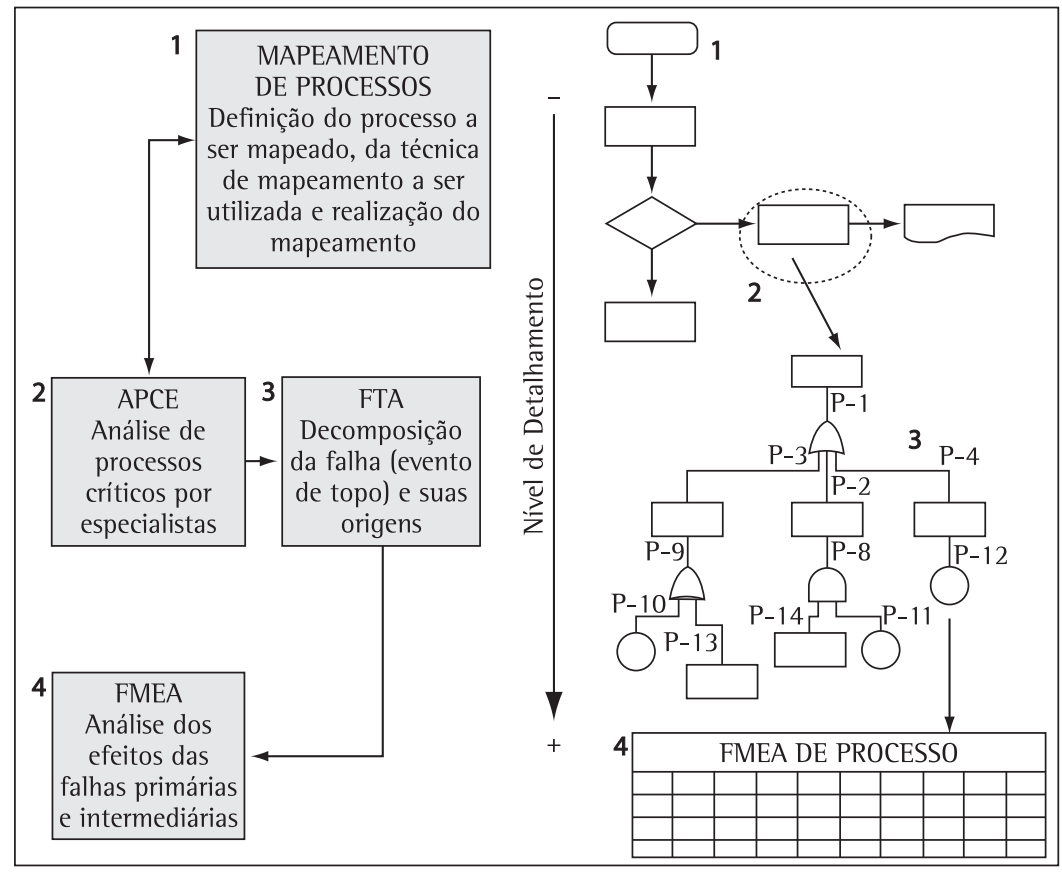

Figura 3. Proposta do Modelo Integrativo de Mapeamento de Processos e Falhas. 
um resumo dos objetivos, da forma procedimental e das características básicas de cada uma das quatro ferramentas utilizadas para a metodologia de mapeamento de falhas proposta. As ferramentas estão ordenadas segundo a sequência lógica de abstração e detalhamento: à medida que uma nova ferramenta é empregada, aumenta o nível de detalhamento. Vale ressaltar que o modelo de análise de falhas proposto pela implementação combinada das quatro ferramentas sugere uma interdependência entre elas, e aquela de nível maior, é um desdobramento ou detalhamento daquela imediatamente anterior.

\section{Aplicação do modelo integrativo em um caso prático}

0 trabalho foi desenvolvido segundo o binômio monitoramento e intervenção. 0 ciclo virtuoso de melhoria possibilitado pelo PDCA refere-se a acompanhar (identificação, observação, análise, mensuração) e intervir (plano de ação). 0 método de pesquisa utilizado foi a Pesquisa-ação, uma vez que, embora nas etapas de identificação até a análise o pesquisador tenha se mantido como um mero observador, ocorreu alteração no sistema em estudo na etapa final. A identificação considerou as várias técnicas de mapeamento de processos com o auxílio de especialistas para a seleção daqueles considerados críticos. A técnica de pesquisa considerou a observação direta e o uso de entrevistas realizadas em três reuniões - segundo a abordagem do brainstorming - com quatro gestores do ambiente produtivo estudado. A primeira reunião foi de cunho preliminar e objetivou apresentar o escopo do trabalho, seus objetivos e limitações, critérios de criticidade, além dos primeiros esboços relativos aos processos candidatos a mapeamento. A segunda reunião considerou uma pré-análise dos especialistas e a reunião final considerou os mapas dos críticos já definidos e as análises tanto das árvores de falhas quanto dos dados já computados dos modos e efeitos de falhas. Pequenas sugestões foram incorporadas nessa última reunião.

A utilização do Modelo Integrativo de Mapeamento de Processos e de Falhas é ilustrada por meio de aplicação em um cartório extrajudicial, privado, que opera por delegação do Poder Público situado na cidade de Varginha/MG, tendo na lavratura de escrituras sua principal atividade.

A atividade notarial é respaldada no exercício da palavra da lei aplicada aos fatos pela tutela estatal (CAHALl et al., 2007). Segundo Marques (2000), a atividade notarial constitui serviço público delegado pelo Estado a juristas profissionais que devem se dedicar à atividade genérica de administração dos direitos privados, a que também se prende a jurisdição voluntária, ou seja, à prevenção do litígio (SILVA, 1998).

Quadro 1. Características, procedimentos e objetivos das técnicas pesquisadas.

\begin{tabular}{|c|c|c|c|c|}
\hline & $\begin{array}{c}\text { Mapeamento de } \\
\text { processo }\end{array}$ & APCE & FTA & FMEA \\
\hline 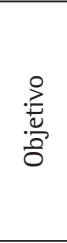 & $\begin{array}{l}\text { ldentificar as diversas } \\
\text { etapas de um processo, } \\
\text { na sequência que elas } \\
\text { ocorrem; expor os } \\
\text { detalhes do processo } \\
\text { de modo gradual e } \\
\text { controlado. } \\
\end{array}$ & $\begin{array}{l}\text { ldentificar as atividades críticas } \\
\text { de um processo mapeado; poupar } \\
\text { tempo e proporcionar economia } \\
\text { de recursos com o desdobramento } \\
\text { da FTA e FMEA somente para os } \\
\text { processos críticos. }\end{array}$ & $\begin{array}{l}\text { ldentificar as causas } \\
\text { primárias das falhas; } \\
\text { elaborar uma relação } \\
\text { lógica entre falhas } \\
\text { primárias e falha final } \\
\text { do produto; analisar a } \\
\text { confiabilidade do sistema. } \\
\end{array}$ & $\begin{array}{l}\text { ldentificar as falhas } \\
\text { críticas em cada } \\
\text { componente, suas } \\
\text { causas e consequências; } \\
\text { hierarquizar as falhas; } \\
\text { analisar a confiabilidade } \\
\text { do sistema. } \\
\end{array}$ \\
\hline 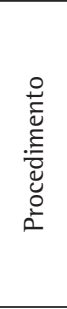 & $\begin{array}{l}\text { Colocar em um gráfico } \\
\text { o processo de um } \\
\text { setor, departamento } \\
\text { ou organização, } \\
\text { para orientação } \\
\text { em suas fases de } \\
\text { avaliação, desenho e } \\
\text { desenvolvimento. }\end{array}$ & $\begin{array}{l}\text { Analisar todos os processos e } \\
\text { detectar aqueles que, em caso de } \\
\text { falhas, compromete o objetivo } \\
\text { final do processo, ou seja, } \\
\text { identificar os processos críticos. } \\
0 \text { método Delphi pode ser um } \\
\text { instrumento metodológico para } \\
\text { a condução das discussões dos } \\
\text { especialistas. }\end{array}$ & $\begin{array}{l}\text { ldentificar a falha (evento) } \\
\text { que é detectada pelo } \\
\text { usuário do produto; } \\
\text { relacionar essa falha com } \\
\text { falhas intermediárias e } \\
\text { eventos mais básicos por } \\
\text { meio de símbolos lógicos. }\end{array}$ & $\begin{array}{l}\text { Analisar as falhas em } \\
\text { potencial de todos } \\
\text { os elementos do } \\
\text { sistema, e previsão das } \\
\text { consequências; relacionar } \\
\text { as ações corretivas (ou } \\
\text { preventivas) a serem } \\
\text { tomadas. }\end{array}$ \\
\hline 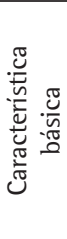 & $\begin{array}{l}\text { Melhor método } \\
\text { para visualizar o } \\
\text { desencadeamento } \\
\text { das atividades de um } \\
\text { processo; a observação } \\
\text { é efetuada em nível } \\
\text { macro. }\end{array}$ & $\begin{array}{l}\text { Todos os processos são passíveis } \\
\text { de análise; o enfoque é dado } \\
\text { aos processos críticos; elimina } \\
\text { trabalhos desnecessários com } \\
\text { o mapeamento de falhas de } \\
\text { processos não críticos. }\end{array}$ & $\begin{array}{l}\text { Melhor método para } \\
\text { análise individual de } \\
\text { uma falha especifica; o } \\
\text { enfoque é dado à falha } \\
\text { final do sistema. }\end{array}$ & $\begin{array}{l}\text { Pode ser utilizado } \\
\text { na análise de falhas } \\
\text { simultâneas ou } \\
\text { co-relacionadas; todos os } \\
\text { componentes do sistema } \\
\text { são passíveis de análise. }\end{array}$ \\
\hline
\end{tabular}


Vale acrescentar que a utilização desta abordagem em processos de serviços, especificamente da área jurídica, não deixa de ser auspiciosa quanto à abrangência de sua aplicabilidade. A aplicação de técnicas de mapeamento ainda carece de casos ilustrativos, haja vista a carência, senão inexistência, de casos aplicativos comprobatórios.

Como objeto de estudo, adota-se as transações imobiliárias, exatamente por se tratar de um processo crítico e de grande relevância, conforme foi evidenciado pelas pessoas entrevistadas (especialistas do cartório alvo do estudo). É de responsabilidade do titular do serviço notarial legitimar, por fé pública, as transações realizadas, cumprindo fielmente a vontade das partes envolvidas. Na prática, os fundamentos do procedimento notarial estão escorados sobre a longa tradição e costumes dos tabeliães. Estes costumes estão positivados, em muito Estados, nas normas de serviço do juízo competente, via de regra, editadas pela Corregedoria-Geral dos Tribunais de Justiça (CAHALl et al., 2007). Em breve resumo, o procedimento notarial resume-se à Rogatória, que consiste na solicitação do atendimento, feita oralmente e já com a entrega de documentos ou autorização para que o tabelião proceda a todos os atos tendentes à lavratura; Minuta, na qual o tabelião redige um documento provisório, que é discutida e aprovada pelos clientes; Protocolo, momento em que o tabelião lavra o ato em livro próprio; Conclusão, quando o ato é assinado pelas partes, pelo escrevente (se houver) e pelo tabelião; e, Circulação e Conservação, que é a expedição do documento definitivo ao cliente, e a conserva do documento assinado, para publicidade futura.

Assim, o tabelião necessita juntar toda a documentação necessária, lavrar o documento em livro próprio, colher as assinaturas de todos os envolvidos e Thes entregar uma cópia do documento, denominada de "traslado", que deverá ser encaminhada para registro no Serviço Registral Imobiliário.

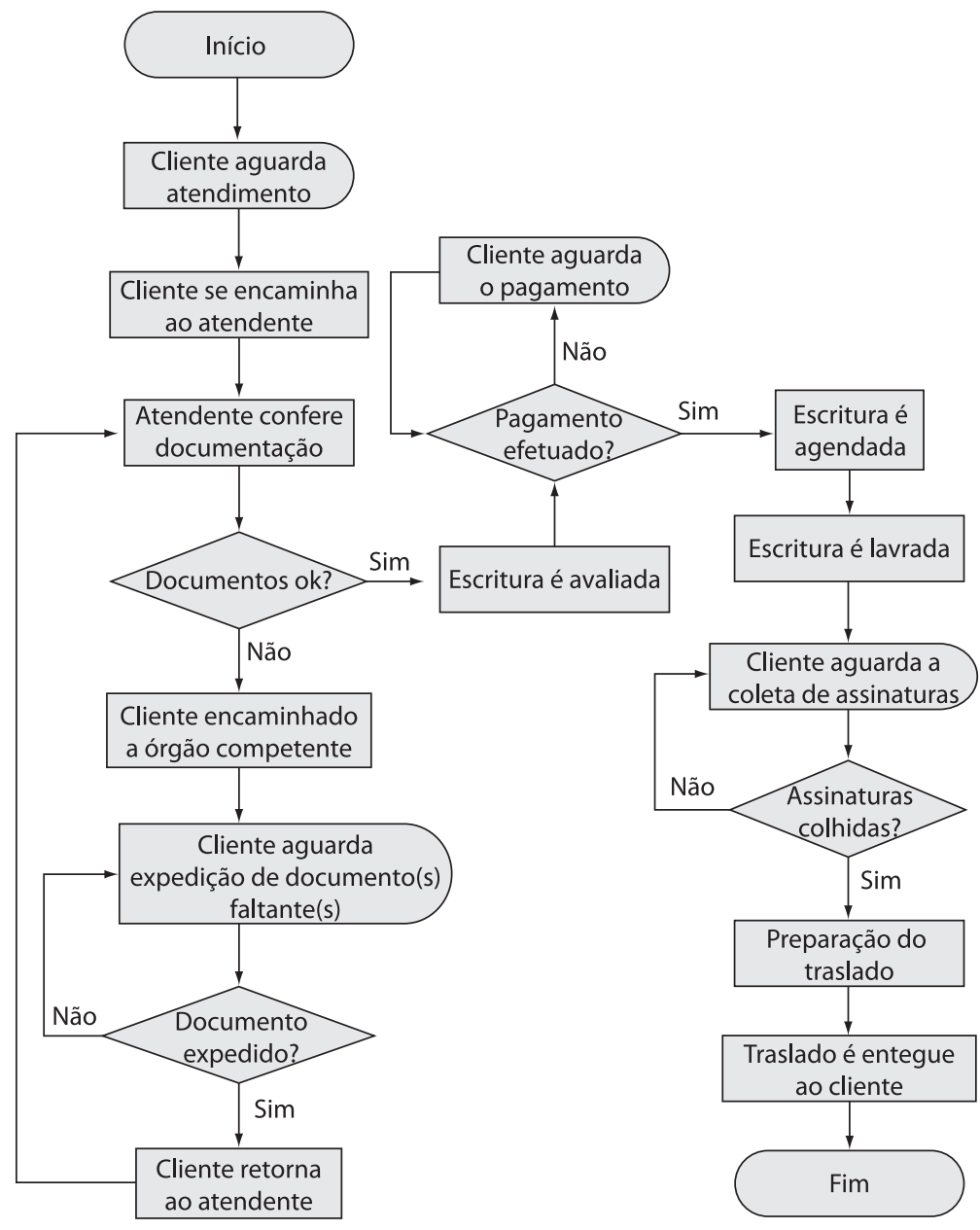

Figura 4. Fluxograma do processo de lavratura de escrituras. 
A coleta de assinaturas se constitui em uma importante fase do processo, pois, segundo apregoam os ritos obrigatórios instituídos à lavratura, nesse momento a escritura deverá ser lida integralmente aos contratantes, que conferem a documentação inserida, julgam ter entendido o que ali se contém, e declaram ser a expressão fidedigna de suas vontades.

Minimizar possíveis erros na confecção desse documento é de suma importância para a conclusão da transação, já que a ocorrência de inconsistências no documento gerado poderá resultar na impossibilidade de efetivação de registro junto ao serviço imobiliário; restrições, impedimentos ou solicitação de esclarecimentos junto a autoridades do poder público municipal, estadual e federal, devido às divergências de informações; na obstrução da emissão de certidões diversas; e, em caso extremo, na nulidade da transação, requerida em juízo e nos casos previstos no Código Civil Brasileiro pela inobservância dos "Princípios do Direito Notarial" ou descumprimento das competências previstas na Lei Notarial (Lei 9.935/1994).

0 processo de lavratura de escrituras pressupõe etapas bem definidas, solicitação/emissão de documentação, confecção da escritura, coleta de assinaturas, lavratura e preparação/entrega do traslado. Devido à já consolidada aplicação de fluxogramas em representar fases distintas de um processo, com simbologia apropriada, este foi utilizado para uma representação inicial do processo.

Por meio dessa técnica (Fluxograma de Processo), representada na Figura 4, a tabeliã e a tabeliãsubstituta do referido cartório puderam identificar os pontos críticos do processo de lavratura, que são:

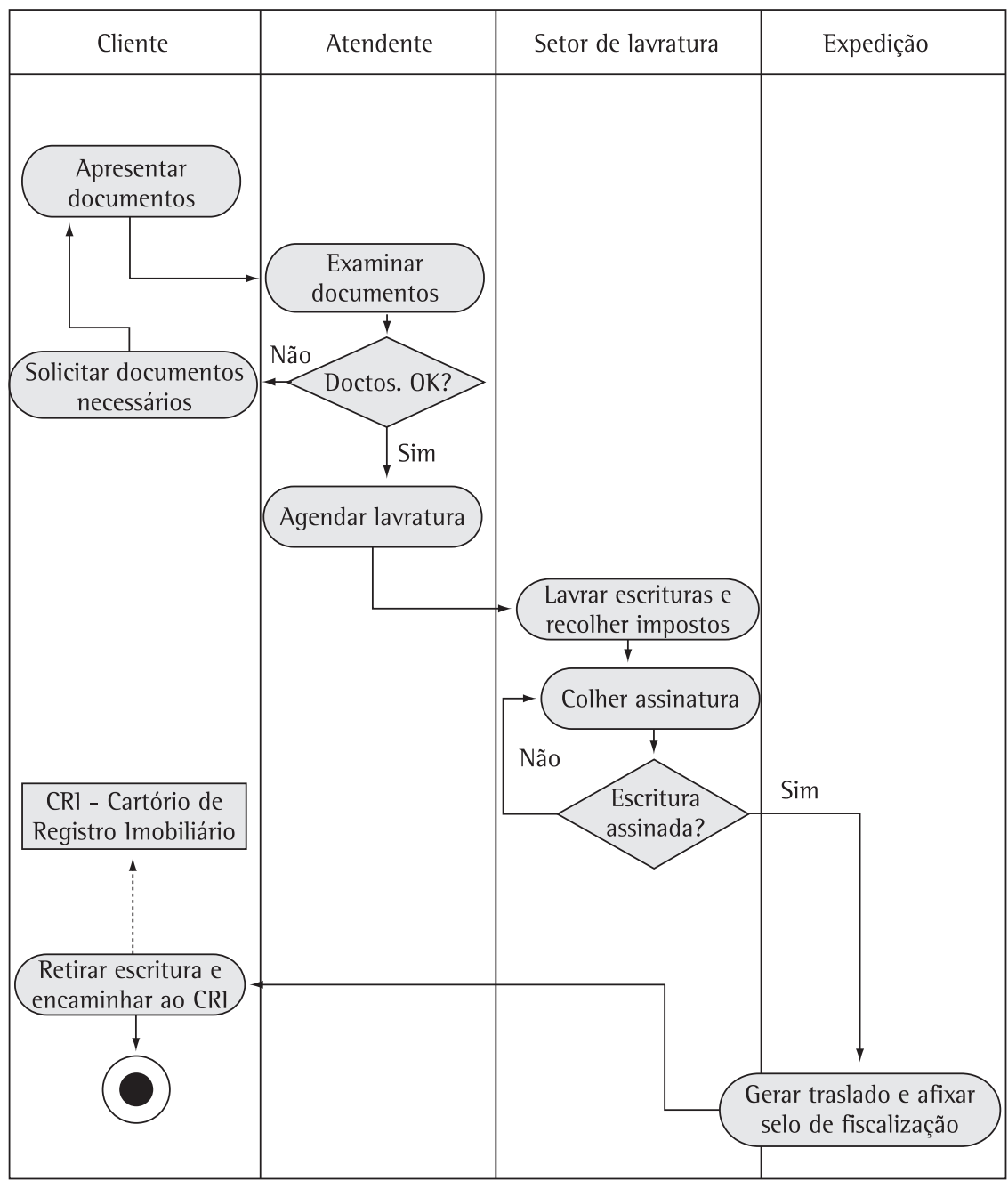

Figura 5. Diagrama sistemático de UML do processo de lavratura de escrituras. 
Quadro 2. Funções, modos de falha e efeitos.

\begin{tabular}{|c|c|c|}
\hline Função & Modo de falha & Efeito \\
\hline $\begin{array}{c}\text { Analisar } \\
\text { documentação. }\end{array}$ & $\begin{array}{c}\text { Agendar escritura sem a } \\
\text { documentação necessária. }\end{array}$ & $\begin{array}{l}\text { Em muitos casos, a concretização da escritura fica comprometida, } \\
\text { devido às inconsistências da documentação entregue ao setor } \\
\text { de lavratura, resultando na impossibilidade de continuação } \\
\text { do processo e, consequentemente, em atrasos na entrega da } \\
\text { escritura. }\end{array}$ \\
\hline $\begin{array}{l}\text { Lavrar } \\
\text { corretamente } \\
\text { a escritura. }\end{array}$ & $\begin{array}{l}\text { Gerar um documento passível } \\
\text { de ações de correção. }\end{array}$ & $\begin{array}{l}\text { Uma escritura lavrada com equívocos gera transtornos e custos } \\
\text { adicionais nas ações de retificação e ratificação, ressalvas e até } \\
\text { mesmo processos civis ajuizados pelas partes. }\end{array}$ \\
\hline $\begin{array}{l}\text { Recolher os } \\
\text { impostos. }\end{array}$ & $\begin{array}{l}\text { Gerar recolhimentos indevidos } \\
\text { ou constatar a ausência deles. }\end{array}$ & $\begin{array}{l}\text { Recolhimentos indevidos ou suas ausências podem resultar em } \\
\text { ações do poder público estadual, impedimento para emissão de } \\
\text { certidões negativas pessoais e aplicação de severas multas. }\end{array}$ \\
\hline $\begin{array}{l}\text { Entregar dentro } \\
\text { do prazo. }\end{array}$ & Atrasar a entrega. & $\begin{array}{l}0 \text { atraso da entrega do traslado, referente à escritura lavrada pode } \\
\text { gerar prejuízos com viagens, expiração de prazos de validade de } \\
\text { certidões - gerando novos custos, ou implicações com os trâmites } \\
\text { burocráticos das instituições financeiras, no caso de empréstimo. }\end{array}$ \\
\hline
\end{tabular}

a) A conferência da documentação apresentada etapa necessária para que o processo possa seguir com sua tramitação de praxe;

b) 0 agendamento e posterior lavratura do documento - a lavratura é o fato gerador dos impostos que deverão ser recolhidos aos cofres estaduais;

c) A coleta das assinaturas de todas as partes envolvidas; e

d) A preparação do traslado para expedição.

0 mapeamento realizado pelo Fluxograma de Processo permitiu que todos os integrantes da equipe de análise chegassem à compreensão das etapas impostas ao cliente, na execução dos trâmites legais obrigatórios, de forma clara e concisa. Entretanto, a lógica sequencial expressa pelo Fluxograma de processo teve que ser completada pelo Diagrama Sistemático do UML, uma vez que esta possibilita destacar a participação de numerosos agentes no desenvolvimento do processo por meio de "raias" específicas, como ilustra a Figura 5. A propósito, uma regra candidata seria o Service Blueprint, uma vez que destaca as atividades que não exigem a participação do cliente (back-office). No entanto, para o caso em questão, as raias (atendente, setor de lavratura e expedição) cumpriram adequadamente este papel. Desta forma, prescindindo do mapeamento via Blueprint e sua variante o Mapa de Serviço.

Ainda considerando a seleção da técnica de mapeamento, vale destacar a não utilização das demais técnicas para o caso em questão, a saber:

0 Mapofluxograma nada mais é que a aplicação do fluxograma de processo sobre uma planta baixa. Seu uso se mostra particularmente relevante quando o arranjo físico de instalações é aspecto relevante. Esse não é o caso do processo de serviços extrajudiciais.

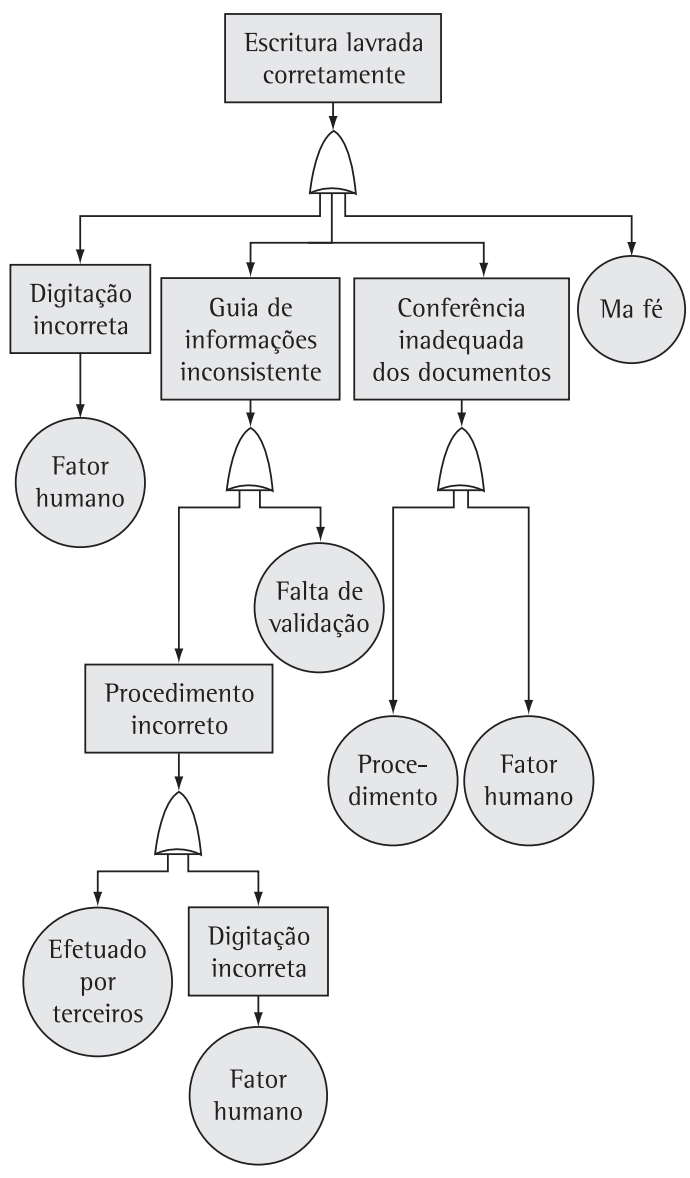

Figura 6. Representação gráfica do FTA.

A família IDEF (Integrated Computer Aided Manufacturing Definition) possui a vocação de atuar em ambientes complexos, normalmente afetos à manufatura, embora Tseng et al. (1999) tenham defendido adaptações no $\operatorname{LEF}(3)$ para 
Quadro 3. Elaboração da FMEA para a Lavratura de Escrituras.

\begin{tabular}{|c|c|c|c|c|c|c|c|c|c|}
\hline \multirow[b]{2}{*}{$\begin{array}{l}\text { Passos } \\
\text { Cíticos }\end{array}$} & \multicolumn{3}{|c|}{ Falhas possiveis } & \multirow[b]{2}{*}{$\begin{array}{l}\text { Controles } \\
\text { atuais }\end{array}$} & \multicolumn{4}{|c|}{ Índices } & \multirow[b]{2}{*}{$\begin{array}{c}\text { Ação corretiva e/ou preventiva } \\
\text { recomendada }\end{array}$} \\
\hline & $\begin{array}{l}\text { Modo } \\
\text { de } \\
\text { falha }\end{array}$ & Efeito & Causas & & 0 & D & $\mathrm{S}$ & RPN & \\
\hline \multirow{6}{*}{ 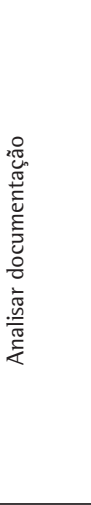 } & \multirow{6}{*}{ 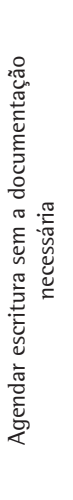 } & \multirow{6}{*}{ 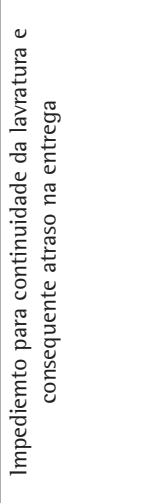 } & Acúmulo de funções & Inexistente & 8 & 1 & 5 & 40 & Redistribuição de funções \\
\hline & & & $\begin{array}{l}\text { Falta de qualificação da } \\
\text { mão de obra }\end{array}$ & Inexistente & 6 & 3 & 4 & 72 & $\begin{array}{l}\text { Treinamento nos procedimentos } \\
\text { adotados, no ferramental e na } \\
\text { legislação pertinente }\end{array}$ \\
\hline & & & $\begin{array}{l}\text { Falta de detalhamentos } \\
\text { dos procedimentos de } \\
\text { conferência }\end{array}$ & $\begin{array}{l}\text { Lista de } \\
\text { documentos } \\
\text { obrigatórios }\end{array}$ & 7 & 3 & 3 & 63 & $\begin{array}{l}\text { Revisão dos procedimentos iniciais } \\
\text { de lavratura }\end{array}$ \\
\hline & & & $\begin{array}{l}\text { Falta de atualização } \\
\text { dos procedimentos de } \\
\text { conferência }\end{array}$ & Inexistente & 7 & 3 & 3 & 63 & $\begin{array}{l}\text { Agendamento de reuniões para } \\
\text { revisão e atualização (Gates) }\end{array}$ \\
\hline & & & $\begin{array}{l}\text { Ausência de controles da } \\
\text { inspeção dos serviços }\end{array}$ & Inexistente & 7 & 6 & 3 & 126 & Adoção de controles de inspeção \\
\hline & & & Má fé & Inexistente & 1 & 10 & 10 & 100 & $\begin{array}{l}\text { Buscar ferramentas de validação } \\
\text { e conferência eficazes para } \\
\text { coibir possívies fraudes }\end{array}$ \\
\hline \multirow{5}{*}{ 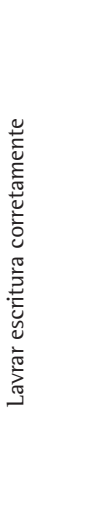 } & \multirow{5}{*}{ 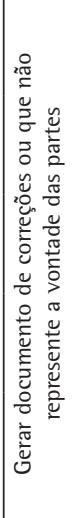 } & \multirow{5}{*}{ 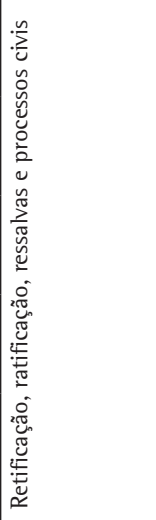 } & Fator humano & Inexistente & 10 & 1 & 5 & 50 & $\begin{array}{l}\text { Adoção de programas de } \\
\text { treinamento (procedimentos e } \\
\text { atendimento) }\end{array}$ \\
\hline & & & Má fé & Inexistente & 1 & 10 & 10 & 100 & $\begin{array}{l}\text { Buscar ferramentas de validação } \\
\text { e conferência eficazes para } \\
\text { coibir possívies fraudes }\end{array}$ \\
\hline & & & $\begin{array}{l}\text { Preenchimento da guia } \\
\text { de informação realizado } \\
\text { por terceiros }\end{array}$ & Inexistente & 3 & 7 & 5 & 105 & \multirow[t]{2}{*}{$\begin{array}{l}\text { Implementar rigorosos } \\
\text { procedimentos de conferência }\end{array}$} \\
\hline & & & $\begin{array}{l}\text { Falha nos procedimetos } \\
\text { de conferência }\end{array}$ & $\begin{array}{l}\text { Lista de } \\
\text { documentos } \\
\text { obrigatórios }\end{array}$ & 5 & 5 & 5 & 125 & \\
\hline & & & $\begin{array}{l}\text { Falta de validação } \\
\text { dos documentos } \\
\text { apresentados }\end{array}$ & $\begin{array}{l}\text { Programa de } \\
\text { validação e } \\
\text { conferência } \\
\text { via internet }\end{array}$ & 2 & 1 & 3 & 6 & $\begin{array}{l}\text { Buscar ferramentas de validação } \\
\text { e conferência eficazes }\end{array}$ \\
\hline \multirow{3}{*}{ 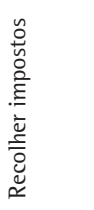 } & \multirow{3}{*}{ 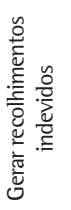 } & \multirow{3}{*}{ 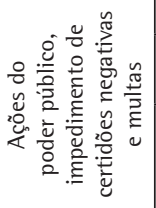 } & Fator humano & Inexistente & 10 & 1 & 5 & 50 & \multirow{2}{*}{$\begin{array}{l}\text { Designação e treinamento dos } \\
\text { responsáveis pelos recolhimentos } \\
\text { e lançamentos do Livro Caixa }\end{array}$} \\
\hline & & & $\begin{array}{l}\text { Erro de lançamento do } \\
\text { Livro Caixa mensal } \\
\end{array}$ & Inexistente & 4 & 6 & 8 & 192 & \\
\hline & & & $\begin{array}{l}\text { Erro na informação do } \\
\text { valor fiscal da escritura }\end{array}$ & Inexistente & 4 & 6 & 10 & 240 & $\begin{array}{l}\text { lmplementação da rotina pós- } \\
\text { lavratura }\end{array}$ \\
\hline \multirow{5}{*}{ 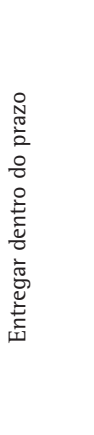 } & \multirow{5}{*}{ 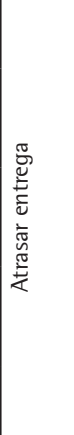 } & \multirow{5}{*}{ 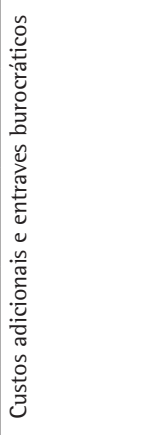 } & Fator humano & Inexistente & 10 & 3 & 5 & 150 & $\begin{array}{l}\text { Investir em treinamentoe } \\
\text { concientização dos efeitos }\end{array}$ \\
\hline & & & $\begin{array}{l}\text { Falha nos procedimnetos } \\
\text { de conferência }\end{array}$ & $\begin{array}{l}\text { Lista de } \\
\text { documentos } \\
\text { obrigatórios }\end{array}$ & 10 & 5 & 3 & 150 & $\begin{array}{l}\text { Revisão dos procedimentos } \\
\text { adotados e implementação de } \\
\text { controles mais eficazes }\end{array}$ \\
\hline & & & $\begin{array}{l}\text { Informações } \\
\text { insuficientes }\end{array}$ & Inexistente & 6 & 2 & 3 & 36 & $\begin{array}{l}\text { Implementar lista de } \\
\text { informações obrigatórias à } \\
\text { lavratura }\end{array}$ \\
\hline & & & Falta de pagamento & Inexistente & 5 & 3 & 10 & 150 & $\begin{array}{l}\text { Implementar bloqueio de } \\
\text { agendamento sem a devida } \\
\text { quitação da lavratura }\end{array}$ \\
\hline & & & Falta de assinatura & Inexistente & 3 & 3 & 10 & 90 & $\begin{array}{l}\text { Implementar Call center para } \\
\text { contato com os contratantes }\end{array}$ \\
\hline \multicolumn{3}{|c|}{ Ocorrência } & \multicolumn{2}{|c|}{ Detecção (D) } & \multicolumn{5}{|c|}{ Severidade (S) } \\
\hline \multicolumn{2}{|c|}{ Improvável } & 1 & Alta & 1 & \multicolumn{4}{|c|}{ Apenas perceptível } & 1 \\
\hline \multicolumn{2}{|c|}{ Muito pequena } & 2 a 3 & Moderada & 2 a 3 & \multicolumn{4}{|c|}{ Pouca importância } & 2 a 3 \\
\hline \multicolumn{2}{|c|}{ Moderada } & 4 a 6 & Pequena & 4 a 6 & \multicolumn{4}{|c|}{ Moderada } & 4 a 6 \\
\hline \multicolumn{2}{|c|}{ Alta } & 7 a 8 & Muito pequena & 7 a 8 & \multicolumn{4}{|c|}{ Grave } & 7 a 8 \\
\hline Alarm & ante & 9 a 10 & Improvável & 9 a 10 & & Gra & sima & & 9 a 10 \\
\hline Graus & le priori & dade de risco & Baixo - 1 a 100 & Moderado & . & 300 & & & Alto - 301 a 1000 \\
\hline
\end{tabular}


atender a processos complexos em serviços sujeitos a alta dinamicidade. Este não é o caso do processo em pauta.

Seguindo a orientação da APCE, a partir da compreensão do processo, foram identificadas suas funções primordiais - analisar documentação, lavrar corretamente o documento, recolher os impostos e entregar o documento lavrado dentro do prazo determinado - e os pontos críticos foram analisados pelos especialistas, que apontaram onde as falhas poderiam ocorrer mais e com maior grau de relevância.

Assim, seguindo o que foi proposto, iniciou-se a análise de falhas por meio do mapeamento de processo de lavratura de escritura, para criar a compreensão das etapas que devem ser alcançadas até a sua conclusão.

Apoiando-se nas funções, agora conhecidas, procurou-se determinar por meio de variadas reuniões em que o grupo discutiu quais seriam os modos de falha e os efeitos destes. 0 Quadro 2 apresenta as conclusões desta etapa, apresentando a função, os modos de falha e seus efeitos.

No passo seguinte, utilizou-se a Árvore de Análise de Falhas para identificação dos erros mais relevantes no processo de lavratura de escrituras, com suas respectivas causas/efeitos intermediárias e causas iniciais (falhas primárias). A Figura 6 ilustra a FTA para a função "Lavrar corretamente a escritura".

Finalmente, foi gerada a FMEA (Quadro 3), como último passo do processo de análise do mapeamento de falhas, delineando o seu mais alto nível de detalhamento com todos os modos de falhas, seus efeitos, causas e ações corretivas recomendadas para a lavratura de escrituras.

Como toda FMEA, foram atribuídos valores variando entre 1 e 10, em ordem crescente, para: a) a probabilidade de ocorrência de um dado modo de falha e/ou de uma dada causa; b) para a severidade do impacto de um dado modo de falha sobre o processo; c) para a possibilidade de detecção de um dado modo de falha e/ou causa (ressalta-se que, para a detecção, o valor 1 associa-se à total possibilidade de detecção, enquanto o valor 10 associa-se à possibilidade remota).

0 RPN do formulário FMEA, que indica o grau de risco e prioriza as contra medidas a serem adotadas contra as falhas, é calculado a partir da multiplicação entre as variáveis de ocorrência $(O)$, severidade $(S)$ e detecção $(D)$.

A ponderação dessas variáveis foi atribuída pelos especialistas do cartório que julgaram o nível de relevância de cada um dos elementos levantados na
FMEA - Modo de Falha, Efeito e Causas - para a posterior aplicação do índice RPN.

\section{Ações decorrentes}

Com base nas informações extraídas como resultado da metodologia aplicada foi possível averiguar os pontos críticos no processo estudado.

No exemplo de FMEA apresentado pelo Quadro 3, dentro da função "Lavrar escritura corretamente", pôde-se verificar que a falha nos procedimentos de conferência alcançou o maior score dentre as causas levantadas. A partir dessa conclusão, elaboraram-se sugestões para sua melhoria e recomendações para ações corretivas e/ou preventivas, tais como:

- A revisão dos procedimentos adotados para a conferência da documentação encaminhada à lavratura, a fim de se impor maior rigor a esta etapa;

- Inclusão dos atendentes responsáveis pela conferência em programas de excelência de atendimento;

- Treinamento profissional, tanto nas ferramentas de auxílio à validação da documentação apresentada (sistemas auxiliares ou consultas via Internet), como na legislação pertinente à regulamentação das transações contempladas pelos serviços notariais;

- Busca de instrumentos para coibir possíveis fraudes; e

- Adoção de um programa de bonificações para aqueles que se destacarem no período.

\section{Conclusões}

A adoção da metodologia que integra 0 mapeamento de processo às técnicas FTA e FMEA, bem como a utilização da APCE para a definição dos processos críticos, proporcionaram uma visualização das atividades desencadeadas pelo processo de forma clara e objetiva, o que ressaltou os pontos fortes e fracos do processo em análise. De fato, intervenções puderam ser decididas graças a esse método que se apresentou como um instrumento de auxílio à tomada de decisões. Tal instrumento ensejou um formalismo no processo de análise e tomada de decisão pouco usual no ambiente de trabalho objeto de estudo.

A aplicação combinada destas técnicas no setor de processo de serviços jurídicos, diferente do ambiente fabril em que comumente tais estudos se aplicam, é bastante auspiciosa como contribuição de cunho científico. 
Pôde-se concluir, por meio da aplicação prática, que a metodologia proposta, pelo uso integrado com a FTA e FMEA, é pertinente e viável, além de fornecer uma sequência de etapas que auxiliam na compreensão dos processos estudados, na identificação dos pontos críticos de ação, na determinação das falhas e seus efeitos e na elaboração do panorama geral das falhas e efeitos, visando à priorização das medidas de correção, se for o caso, e da consequente mitigação/eliminação das falhas dos processos.

Os processos notariais, pela rigidez dos ritos burocráticos impostos pela legislação pertinente, podem e devem se adaptar aos avanços em tecnologia e sistemas de informação. Este artigo apresenta um modelo de características integrativas inovadoras e o aplica em processos notariais, um caso pouco explorado tanto na prática quanto na pesquisa acadêmica em serviços.

\section{Referências}

ALMEIDA, D. A.; FAGUNDES, L. D. Aplicação da Gestão do Conhecimento no mapeamento de falhas em concessionária do setor elétrico. Revista Produto \& Produção, v. 8, n. 3, p. 63-80, 2005.

ALMEIDA, D. A.; PINHO, A. F. Indicador de desempenho intra-falha - uma abordagem racionalizadora para liberar capacidade produtiva em empresas do setor elétrico. In: CLAGTEE, 6, 2005, Mar Del Plata - Argentina. Anais...

ALMEIDA, D. A. et al. Gestão do Conhecimento na análise de falhas: mapeamento de falhas através de sistema de informação. Revista Produção, v. 15, n. 1, p. 171-188, 2006.

ARAUJO, L. O. C.; AQUINO, J. P. R.; ROTONDARO, R. G. Análise e Aplicabilidade das Ferramentas da Qualidade no Serviço de Fôrmas como Auxílio ao Planejamento para Produção. In: ENEGEP, 21, 2001, Salvador - BA. Anais...

BARNES, R. M. Estudo de movimentos e de tempos. Tradução da $6^{a}$ edição americana. 9a reimpressão. São Paulo: Edgard Blücher, 2004.

BASTOS, A. L. A. FMEA como Ferramenta de Prevenção da Qualidade em Produtos e Processos - Uma Avaliação da Aplicação em um Processo Produtivo de Usinagem de Engrenagem. In: ENEGEP, 26, 2006, Fortaleza - CE. Anais...

BLACHE, M. K.; SHRIVASTAVA, B. A. Defining Failure of Manufacturing \& Equipment. In: ANNUAL RELIABILITY AND MAINTAINNABILITY SYMPOSIUM, 1994. Proceedings... p. 69-75.

CAHALl, F. J. et al. Escrituras Públicas: separação, divórcio, inventário e partilha consensuais: análise civil, processual civil, tributária e notarial. São Paulo: Editora Revista dos Tribunais, 2007.

CHEUNG, Y.; BAL, J. Process analysis techniques and tools for business improvements. Business Process Management Journal, v. 4, n. 4, p. 274-290, 1998.
FAGUNDES, L. D.; ALMEIDA, D. A. Mapeamento de falhas em concessionárias do setor elétrico: padronização, diagramação e parametrização. In: SIMPEP, 11, 2004, Bauru - SP. Anais..

FERNANDES, J. M. R.; REBELATO, M. G. Proposta de um método para integração entre QFD e FMEA. Revista Gestão e Produção, v. 13, n. 2, p. 245-259, 2006.

FITZSIMMONS, J. A.; FITZSIMMONS, M. J. Administração de Serviços: operações, estratégia e tecnologia da informação. 2 ed. Porto Alegre: Bookman, 2000.

GOH0, J.; MACASKILL, P.; MCGEACHIE, P. Using a Panel of Experts to Enrich Planning of Distance Education. Journal of distance education revue de l'éducation à distance, v. 18, n. 1, p. 1-18, 2003.

GREEN, K. C.; ARMSTRONG, J. S.; GRAEFE, A. Methods to Elicit Forecasts from Groups: Delphi and Prediction Markets Compared Forthcoming. The International Journal of Applied Forecasting, 22 september, 2007.

GROVER, V.; KETTINGER, W. J. Business process change. Reengineering concepts, methods and technologies. Harrisburg: Idea Group Publishing, 1995.

HELMAN, H.; ANDERY, P. R. P. Análise de Falhas. Aplicação de FMEA e FTA. Belo Horizonte: Editora Fundação Cristiano Ottoni, 1995.

HUNT, V. D. Process Mapping: How to Reengineer your Business Process. New York: John Wiley \& Sons, 1996.

INAKl, H. S.; LANDÍN, G. A.; FA, M. C. A Delphi study on motivation for ISO 9000 and EFQM. International Journal of Quality \& Reliability Management, v. 23, n. 7, p. 807-827, 2006.

JUNG, W. S.; YANG, J.; HA, J. Development of measures to estimate truncation error in fault tree analysis. Reliability Engineering and System Safety, v. 90, n. 1, p. 30-36, 2005.

KINGMAN-BRUNDAGE, J. Service mapping: back to basics. In: Understanding services management. New York: John Wiley \& Sons, 1995.

LEAL, F. Um diagnóstico do processo de atendimento a clientes em uma agência bancária através de mapeamento do processo e simulação computacional. Itajubá, MG, 2003. Dissertação (Mestrado em Engenharia de Produção) - Universidade Federal de Itajubá.

LEAL, F.; PINHO, A. F.; CORRÊA, K. E. S. Análise comparativa de técnicas de mapeamento de processo aplicadas a uma célula de manufatura. In: SIMPEP, 10, 2003, Bauru - SP. Anais...

LIN, C.; WANG, J. J. Hybrid fault tree analysis using fuzzy sets. Reliability Engineering and System Safety, v. 58, n. 3, p. 205-213, 1997.

LONG, W.; SATO, Y.; HORIGOME, M. Quantification of sequential failure logic for fault tree analysis. Reliability Engineering and System Safety, v. 67, n. 3, p. 269-274, 2000.

MACCARTHY, B. L.; ATTHIRAWONG, W. Factors affecting location decisions in international operations: a Delphi study. International Journal of Operations \& Production Management, v. 23, n. 7, p-794-818, 2003.

MAHANTI, R.; ANTONY, J. Confluence of six sigma, simulation and software development. Managerial Auditing Journal, v. 20, n. 7, p. 739-762, 2005.

MARQUES, J. F. Instituições de direito processual civil. Campinas: Millenium, 2000. 
MAYER, R. J.; PAINTER, M. K.; WITTE, P. S. IDEF family of methods for concurrent engineering and business re-engineering applications. College Station, TX,: Knowledge Based Systems, Inc., 1992.

MELLO, C. H. P.; SALGADO, E. G. Mapeamento dos processos em serviços: estudo de caso em duas pequenas empresas da área de saúde. In: ENEGEP, 25, 2005, Porto Alegre. Anais...

OKOLI, C.; PAWLOWSKI, S. D. The Delphi method as a research tool: an example, design considerations and applications. Information \& Management, v. 42 n. 1, p. 15-29, 2004.

PALADY, P. FMEA Análise dos Modos de Falha e Efeitos. São Paulo: IMAN, 1997.

PINHO, A. F.; LEAL, F.; ALMEIDA, D. A. A Integração entre o Mapeamento de Processo e o Mapeamento de Falhas: dois casos de aplicação no setor elétrico. In: ENEGEP, 26, 2006, Fortaleza - CE. Anais...

RATH, F. Tools for developing a quality management program: proactive tools (process mapping, value stream mapping, fault tree analysis, and failure mode and effects analysis). International Journal Radiation Oncology Biology Physics, v. 71, n. 1, p. 187-190, 2008.

RAUSAND, M.; OIEN, K. The basic concepts of failure analysis. Reliability Engineering and System Safety, v. 53, n. 1, p. 73-83, 1996

SHAHIN, A. Integration of FMEA and the Kano model: An exploratory examination. International Journal of Quality \& Reliability Management, v. 21, n. 7, p. 731-746, 2004.

SHARMA, R. K.; KUMAR, D.; KUMAR, P. Modeling and analysing system failure behaviour using RCA, FMEA and NHPPP models. International Journal of Quality \& Reliability Management, v. 24, n. 5, p. 525-546, 2007.

SHARMA, R. K.; KUMAR, D.; KUMAR, P. Systematic failure mode effect analysis (FMEA) using fuzzy linguistic modeling. International Journal of Quality \& Reliability Management, v. 22, n. 9, p. 986-1004, 2005.
SIlva, 0. A. B. Curso de Processo Civil - Processo de conhecimento. 4 ed. São Paulo: Editora RT, 1998.

SLACK, N.; CHAMBERS, S.; JOHNSTON, R. Administração da Produção. São Paulo: Atlas, 2002.

TENG, S. G. et al. Implementing FMEA in a collaborative supply chain environment. International Journal of Quality \& Reliability Management, v. 23 n. 2, p. 179-196, 2006.

TSENG, M. M.; QINHAl, M.; SU, C. J. Mapping Customers' Service Experience for Operations Improvement. Business Process Management Journal, v. 5, n. 1, p.50-64, 1999.

VERGARA, S. C. Métodos de Pesquisa em Administração. Editora Atlas, São Paulo, 2006.

VOLLERTT JUNIOR, J. R. Confiabilidade e falhas de campo: um estudo de caso para melhoria da confiabilidade de um produto e do reparo, através de um procedimento sistemático de coleta de dados. Santa Catarina, Florianópolis, 1996. Dissertação (Mestrado em Engenharia de Produção) - Universidade Federal de Santa Catarina.

WILCOX, P. A.; GURAU, C. Business modelling with UML: the implementation of CRM systems for online retailing. Journal of Retailing and Consumer Services, v. 10, n. 3, p.181-191, 2003.

$\mathrm{XIE}$, M. et al. Optimum prioritisation and resource allocation based on fault tree analysis. International Journal of Quality \& Reliability Management, v. 17, n. 2, p. 189-199, 2000.

YANG, C. et al. A study on applying FMEA to improving ERP introduction an example of semiconductor related industries in Taiwan. International Journal of Quality \& Reliability Management, v. 23, n. 3, p. 298-322, 2006.

YUGl, T.; TAGAMI, K.; YANAGl, S. Calculating top event probability of a fault tree with many repeated events. Journal of Quality in Maintenance Engineering, v. 12 n. 4, p. 364-372, 2006.

\title{
Fault Mapping Integrated Methodology: an approach to using process mapping with FTA and FMEA techniques, and supported by expert's critical analysis
}

\begin{abstract}
Faults are understood as non-conformities in productive activities. Therefore, the study of approaches that aim to eliminate and/or mitigate failures is important and even considered essential. Since the literature on this subject suggests the use of techniques for fault control and prevention, the present article aims to propose integration among process mapping, Fault Tree Analysis (FTA), and the Failure Modes and Effects Analysis (FMEA), as means to reducing and/or eliminating faults. The proposed approach considers process mapping as the starting point, and FMEA, as the concluding stage. The method presented is conducted by means of a proposed technique called Expert Critical Process Analysis. To achieve this goal, bibliographical research was undertaken to enable the conceptualization of each listed technique, followed by an analysis of their integration. The proposed methodology is applied in a case study.
\end{abstract}

\section{Keywords}

Fault mapping. Extra-juridical services. FMEA. FTA. 